dar sentido às decisōes, dar legitimidade às práticas e [que], por fim, tornou-se um modelo a ser difundido" (p.129). A mobilização social, cultural e política em torno da cidade - entendida como fórum de interesse comum e como espaço de desenvolvimento econômico - traduzir-se-á em participação através do consenso como técnica de governo. A constituição do CIDEU - Centro Iberoamericano de Desarrollo Estratégico Urbano - em 1993 expressa de forma lapidar a possibilidade aberta de fazer circular, através de consultoria especializada, este novo produto da cesta de serviços: o plano estratégico de cidades. É curioso constatar que, no documento final da III Cumbre Iberoamericana de Jefes de Estado y de Gobierno, realizada em Salvador (BA) em julho de 1993, o tópico n.38 versa sobre as grandes cidades. Afirma-se que

Hemos sido informados de las conclusiones de la I Conferencia de Ciudades para el Siglo XXI, realizada en Río de Janeiro los días 3 al 5 de junio de 1993 (anexo n.8), donde fueron examinados los problemas urbano-ambientales que afectan particularmente a las grandes ciudades latinoamericanas. Se enfatizó, en dicha ocasión, la importancia del intercambio amplio y sistemático de experiencias en esa área y la necesidad de que las agencias internacionales de desarrollo y reconstrucción otorguen atención a los esfuerzos e iniciativas que realizan por las comunidades locales iberoamericanas. La Conferencia de Ciudades apoyó la iniciativa de crear el Centro Iberoamericano de Desarrollo Estratégico Urbano (CIDEU), en Barcelona. ${ }^{1}$

É nessa perspectiva que trabalha o quarto capítulo, "Rio de Janeiro: elites políticas e disputas intelectuais", no qual novamente atravessamos o Atlântico, mas agora também o Equador. A experiência da elaboração do Plano Estratégico da Cidade do Rio de Janeiro (1993-1995), que inaugura no país essa forma de ação pública sobre as cidades, será abordada com riqueza analítica e ineditismo de informaçōes, dessa vez contando também com diversas entrevistas realizadas com seus principais protagonistas. Contexto, interpretações, articulações, tensionamentos, transformações, decisões e encaminhamentos: o

1 Disponível em <http://www.oei.es/iiicumbr.htm>. Acesso em 07/02/2011. processo de construção do PECRJ ganha nitidez; e é interessante observar como a formulação teórica e propositiva do planejamento estratégico para a cidade deriva da própria compreensão de estratégia adotada por cada dirigente envolvido, e oscila entre escalas e domínios conceituais, indo do alinhamento a um projeto nacional, a uma técnica de governo, ou ainda, a um desenvolvimento urbano com fortes acentos paroquiais. A problematização do espaço e do território também comparece, como ênfase ou como lacuna, a depender das adesões disciplinares de cada produtor intelectual, eles próprios devidamente enquadrados e caracterizados em seu quinhão de capital simbólico.

Nas conclusões do trabalho, "Planejamento Estratégico como Estratégia”, retoma-se teoricamente o percurso analisado, em que cada decisão metodológica dá lugar a uma perspectiva analítica prenhe de possibilidades. Ao eleger estudar a gênese e difusão de um modelo de planejamento a partir de seu espaço social de produção e circulaçãa, diferenciando contextos, agentes, conjunções, interesses e posições, Pedro Novais amplia as possibilidades de abordagem das longas viagens de ideias e de práticas, ultrapassando o simplismo do pensamento endogenista e incorporando-as aos complexos processos intelectuais a que todos estamos submetidos.

\section{PLANO GERAL DE MELHORA- MENTOS DE PORTO ALEGRE: O PLANO QUE ORIENTOU A MODERNIZAÇÃO DA CIDADE}

Célia Ferraz de Souza

Porto Alegre: Armazém Digital, 2010

\section{Rodrigo Santos de Faria \\ Professor Adjunto da FAU-UnB}

Naquele que considero um dos números mais importantes da Revista Espaço \& Debates, o 34, cujo tema é "Cidade e História", um conjunto de pequenos (mas de extrema importância) depoimentos aborda, cada qual em suas especificidades, questões fundamentais para os pesquisadores arquitetos e urbanistas dedicados aos estudos historiográficos. O primeiro deles, denominado "O estatuto da História", de autoria do 
historiador Edgard de Decca, ${ }^{1}$ apresenta uma série de referências balizadas na obra de outro historiador, Paul Veyne. Na parte central do texto, De Decca faz uma referência crucial ao trabalho historiográfico:

o historiador tem que estar ciente de que os eventos históricos não existem por si, não existem como dado natural. Um evento só é histórico numa trama à qual o historiador é capaz de o concatenar [...] o evento é histórico conforme a trama a qual ele pertencer, e haverá tantas tramas quantas nós quisermos, conforme nossa capacidade de inventá-las" (De Decca, 1991, p.8).

$\mathrm{Na}$ sequência dos seus argumentos, De Decca afirma também que "o lugar onde o historiador resume a trama é sempre conceitual". Ou seja, por esta ou aquela trama, se constrói pela narrativa histórica o conceito - por exemplo, o conceito sobre a Revolução Francesa. Nesta perspectiva do trabalho historiográfico, lida-se com um trabalho de conceituação. $\mathrm{O}$ historiador "tem que trabalhar com conceitos, para ter o poder de generalização", ao mesmo tempo que trabalha com a singularidade, com as particularidades. Segundo De Decca, tais dimensões demonstram "que o historiador a todo momento opera com uma lógica da semelhança e, ao mesmo tempo, com a lógica da diferença”, porque cada evento é um evento particular (De Decca, 1991, p.8).

Feita esta consideração sobre os procedimentos teóricos e metodológicos das pesquisas em história (sobretudo aquelas desenvolvidas por profissionais não historiadores de formação), convém adentrar na problemática central deste texto: uma análise, uma intepretação sobre a interpretação desenvolvida por Célia Ferraz de Souza em seu livro "Plano Geral de Melhoramentos de Porto Alegre: o plano que orientou a modernização da cidade", publicado em segunda edição em 2010. Fundamental frisar que outros caminhos interpretativos podem ser feitos sobre esta importante obra para a historiografia do urbanismo brasileiro, especificamente para o urbanismo no Estado do Rio Grande do Sul.

Célia Ferraz apresenta ao leitor, à medida em que sua narrativa dialoga e problematiza com a do-

1 DE DECCA, E. "O Estatuto da História". Revista Espaço \& Debates, Ano XI, n. 34, 1991, p.7-10. cumentação primária pesquisada, conjunturas particulares amalgamadas ao processo histórico que envolve questôes políticas, econômicas, intelectuais e técnicas inerentes à prática profissional urbanística. Estas questôes estão nas bases das intervençōes para modernização das cidades brasileiras, na passagem do século XIX ao XX, por delinear a inserção da nação na economia capitalista internacional, principalmente pela construção (ainda que incipiente) de uma base econômica industrial.

No caso das interveções no território, a modernização é construída mediante implementação de serviços de abastecimento de água e esgoto, reestruturação do sistema viário (em Porto Alegre pela estrutura em "leque", como nos apresenta a autora), implantação de parques, ou ainda, de grandes sistemas de engenharia de circulação, como é o caso do Porto às margens do Guaíba que, comparativamente, teve a mesma importância das Estações Ferroviárias para a produção cafeeira do interior paulista. Da mesma forma, ocorre uma modernização da gestão municipal, sobretudo a partir da constituição liberal Republicana, com a organização da adminstração pública e criação dos setores de urbanismo e obras urbanas nas municipalidades.

Porto Alegre, nesse contexto de reforma administrativa, conforme nos apresenta Célia Ferraz, mantém os mesmos encaminhamentos do restante do país. É o caso da organização da estrutura administrativa em 1892, com a criação da Secretaria da Intendência composta por sete seçôes, uma delas a de Engenharia, que foi transformada em Diretoria de Obras no ano de 1896. Esta Diretoria é a base genealógica institucional da Comissão de Melhoramentos e Embelezamentos de Porto Alegre, criada em 1912, responsável pela elaboração do Plano Geral de Melhoramentos, o objeto central da pesquisa.

No entanto, aqui entram aspectos que configuram particularidades da trama narrada no livro, com processos históricos próprios, não restritos ao Plano Geral de Melhoramentos como peça documental isolada, mas relacionadas às questões políticas, econômicas, técnicas, intelectuais.

Neste ponto está uma contribuição fundamental do trabalho de Célia Ferraz. Ao construir o contexto conceitual dos estudos sobre a modernização das cidades brasileiras no âmbito das problemáticas sanitárias, infraestruturais e administrativas na passagem do 
século XIX-XX, opera a lógica da diferença enunciada por De Decca, no movimento entre a generalização e a singularização. O contexto conceitual sobre a modernização da cidade no Brasil no âmbito do debate das reformas urbanas sanitaristas é aquele no qual operavam-se planos de melhoramentos e embelezamento como ação pontual para solução de determinados "problemas urbanos", ainda não inseridos na dimensão espacial total dos municípios (excluíndo a ação profissional do engenheiro Saturnino de Brito, que já no Plano do Novo Arrabalde pensava uma concepção global da cidade, inclusive com orientação e previsão do crescimento futuro).

Por outro lado, Célia Ferraz nos apresenta toda uma conjuntura de eventos particulares do processo de elaboração do Plano Geral de Melhoramentos de Porto Alegre e a atuação profissional do engenheiroarquiteto João Moreira Maciel na Comissão e no Plano, e anteriormente, quando foi contratado para fazer projetos arquitetônicos.

Afirmo que são eventos, no plural, pois a autora trabalha um conjunto de "eixos de análise" em suas historicidades particulares, concatenando-os numa narrativa que transita de forma particularizada entre esses eixos e, ao mesmo tempo, na conjuntura de modernização da cidade de Porto Alegre. Estes "eixos de análise" estruturam os capítulos do livro, que se organiza em duas partes: a primeira denominada "A concepção", e a segunda, "A realização".

A primeira parte é composta pelos eixos "o projeto de modernização da cidade", "da modernização do porto à modernização da cidade", "o Plano Geral de Melhoramentos e seu autor" e "a revista Egatea: entre a concepção e a execução do Plano”.

Estão nestes capítulos linearmente organizados, o específico e crucial debate sobre o Positivimo Riograndense e seus vínculos com a educação e a orientação política e técnica no Estado; o debate sobre a modernização do Porto às margens do Guaíba e da cidade, até o momento institucional fulcral de criação da Comissão de Melhoramentos; a análise do Plano e a atuação do "autor" do plano, e, por fim, a circulação das ideias, a circulação do pensamento dos profissionais engenheiros pela revista Egatea.

Neste último, explicita-se um procedimento importante de pesquisa, com perguntas-problema formuladas em determinados momentos da narrativa.
Nesse caso, segundo a própria autora, para entender o que teria justificado a retomada do Plano Geral de Melhoramentos e sua implementação em 1924, dez anos depois de sua elaboração.

Sem receios de outro aspecto peremptório que caracteriza a história, a lacunaridade, Célia Ferraz informa que essas perguntas passam pela falta de documentos, ou "falta de dados". Não se trata de uma "falta", mas daquela dimensão lacunar, que passa pelo que existe de vestígio sobre determinado evento e pelo acesso ao mesmo. Nesse sentido, não é possível pensar em "história total", pois, para isso, seria necessária a existência da totalidade de vestígios sobre este ou aquele evento.

Todavia, se há "falta de dados" para analisar a retomada do Plano, houve a possibilidade para trabalhar na segunda parte do livro as obras que foram sendo implantadas desde 1924, mediante processo de adaptação aos vários e específicos momentos políticos, econômicos, urbanísticos e sociais ao longo do século XX.

Sobre a atuação do engenheiro-arquiteto Moreira Maciel, a análise de Célia Ferraz apresenta uma consideração-conclusão que não é fechada, só possível de se realizar em função do contexto específico de cada "eixo de análise" e do contexto geral do Plano:

fica cada vez mais difícil aceitar que esse plano seja um documento isolado e fruto do trabalho de um único homem. A suposição de um trabalho integrado da Comissão que tratava do planejamento da cidade fica cada vez mais aceitável. (Souza, 2010, p.136)

De fato, trata-se de um plano cujas proposições explicitam a articulação entre "o sistema viário e o saneamento com o embelezamento" (p.128), daí a dificuldade de aceitar sua elaboração por um único profissional.

Por fim, é oportuno considerar momentos do texto em que a dimensão analítica entre a conceituação e a particularização fica comprometida. São os momentos em que surgem referências aos processos de "transferência do modelo para diversas partes do mundo, inclusive no Brasil” (p.136) - a referência aqui é ao "modelo haussmanniano". Ainda que pouco influentes no conjunto da obra, ao transitarem em uma suposta homogeneidade das problemáticas e soluçôes adotadas pelos profissionais das diversas nações 
do mundo capitalista, podem levar ao entendimento de não reconhecimento das particularidades, dos processos históricos únicos, das singularidades.

Mas não reconhecer as particularidades é justamente o que Célia Ferraz não faz. Seu texto, por pressuposto, está pautado no diálogo internacional com as especificidades locais, em suas dimensōes políticas, econômicas, sociais e espaciais, nas especificidades da engenharia no contexto riograndense, nas especificidades da formação e atuação do engenheiro-arquiteto João Moreira Maciel, nas especificidades da circulação do pensamento urbanístico pela revista Egatea, nas particularidades que delinearam a retomada e implementação do Plano. Tanto é assim, que, segundo a autora, $o$

Plano Geral de Melhoramentos se insere, então, como documento-chave: além de seu conteúdo estar muito bem circunscrito ao contexto internacional das discussões sobre urbanismo [...] sua execução também representa o desejo de tornar os espaços da cidade permanências concretas do governo positivista na estrutura urbana de Porto Alegre. (Souza, 2010, p.135)

Essa característica, por si só, justifica a leitura do livro; mas, mais que isso, o livro viabiliza, pelas palavras, um passeio pelas ruas, praças, projetos, edifícios, personagens, política e economia da cidade de Porto Alegre. 